\title{
METODE PENEMUAN ALASAN RASIONAL DALAM HUKUM ISLAM (MASALIK AL-'ILLAT)
}

\author{
Muchlis Bahar \\ Lecturer of Syari'ah Faculty at IAIN Imam Bonjol Padang \\ Jl. Prof. Mahmud Yunus Lubuk Lintah Kota Padang, Sumatera Barat 25153 \\ Email : muchlisbahar@gmail.com
}

\begin{abstract}
The main source of Islamic law is the texts from al-Quran and al-Sunnah. To understand the texts in depth and comprehensive in order to find rational reasons underlying a necessary legal provisions with rational reason or logical reason for it in the terminology of Islamic law called 'illat (effective causa). Methods or how to find and search 'illat is a very important thing to be known, especially for people who want to explore and develop Islamic law in accordance with the social changes that occurred throughout the ages. The methods are through law text (nash), fahwa al-Nash, dan Al-Istidlal bi Hukmi AlNash. All methods or how to find a rational reason in this Islamic law ('illat) is ijtihadiyah attempting, the ideas of Muslim jurists and still can be developed in accordance with the times.
\end{abstract}

Keyword: Methods, 'illat, Islamic law, rational, ijtihadiyah.

\begin{abstract}
Abstrak
Sumber utama hukum Islam adalah dari al-Quran dan al-Sunnah. Untuk memahami teks secara mendalam dan komprehensif dalam rangka untuk menemukan alasan rasional yang mendasari ketentuan hukum yang diperlukan dengan alasan yang rasional atau alasan logis untuk itu dalam terminologi hukum Islam disebut 'illat (causa efektif). Metode atau cara menemukan dan mencari 'illat adalah hal yang sangat penting untuk diketahui, terutama bagi orang-orang yang ingin mengeksplorasi dan mengembangkan hukum Islam sesuai dengan perubahan sosial yang terjadi sepanjang zaman. Metode yang melalui teks hukum (nash), fahwa al-Nas, dan Al-Istidlal bi hukmi Al-Nash. Semua metode atau cara untuk menemukan alasan rasional dalam hukum Islam ini ('illat) adalah ijtihadiyah mencoba, ide-ide dari para ahli hukum Islam dan masih dapat dikembangkan sesuai dengan perkembangan zaman.
\end{abstract}

Kata Kunci: Metode, 'illat, hukum Islam, rasional, ijtihadiyah.

\section{PENDAHULUAN}

Sumber utama hukum Islam adalah teks al-Qur'an dan al-Sunnah. Teks (nash) al-Qur'an dan al-Sunnah itu jumlahnya terbatas karena tidak bertambah lagi setelah wafatnya nabi Muhammad, s,a,w. Pada sisi lain berbagai kasus dan persoalan baru terus bermunculan dan berkembang sesuai dengan perkembangan zaman dan kemajuan ilmu pengetahuan dan teknologi. Berbagai kasus dan persoalan baru itu memerlukan ketetapan hukum. Disini para ahli hukum Islam dituntut untuk dapat mengerahkan segala kemampuan berfikir rasional guna menggali dan menemukan hukum dari teks al-Qur'an dan Sunnah yang telah tersedia. 
Kegiatan mengerahkan segala kemampuan rasional oleh ahli hukum Islam dalam terminology Hukum Islam disebut Ijtihad, pelakunya disebut mujtahid. Mujtahid berusaha memahami teks teks al-Qur'an dan al-Sunnah secara mendalam dan komprehensif untuk dapat menemukan alasan rasional yang melandasi suatu ketetapan hukum. Alasan rasional atau alasan logis itu dalam terminology hukum Islam disebut 'illat (causa efektif). Namun, diantara ahli hukum Islam ada yang berpendapat bahwa semua perintah dan larangan Allah dan RasulNya yang tertulis dalam teks-teks al-Qur'an dan Sunnah tidak dapat dicari alasan rasionalnya. Semua perintah yang ada di dalam teks harus dilaksanakan dan semua larangan harus ditinggalkan, tanpa mempertnyakan lebih jauh, mengapa hal ini diperintahkan? Dan mengapa hal itu dilarang?, yang dalam istilah popular disebut "Sami'na wa atho'na" (kami dengar dan kami patuhi). Diantara yang berpendapat seperti itu adalah Ibnu Hazm al-Zhahiri'. Sebaliknya, mayoritas ahli hukum Islam berpendapat bahwa semua perintah dan larangan di dalam teks-teks tersebut mempunyai alasan rasional yang menjadi landasan bagi suatu ketentuan syari'at.

Allah tidak membiarkan manusia begitu saja hidup tanpa aturan dan tujuan. Oleh sebab itu, diutuslah Rasul-RasulNya yang membawa kitab suci untuk menjelaskan aturan dan tujuan hidup tersebut.

Al-Qur'an sebagai kitab suci umat Islam telah menjelaskan hukum-hukum yang mengatur kehidupan manusia untuk mencapai kebahagiaan di dunia dan akhirat. Hukumhukum itu juga dijelaskan oleh Nabi Muhammad SAW melalui Sunnahnya.

Ketentuan hukum yang terdapat pada Teks hukum (nash), baik yang terdapat pada AlQur'an maupun pada Sunnah(Hadits)- tidak ditetapkan begitu saja tanpa mempunyai alasan rasional/logis yang menjadi landasan bagi hukum tersebut. Malah setiap teks hukum itu mempunyai alasan rasional (logis) yang menjadi landasannya sehingga dikenal kaedah yang berbunyi "al-Hukmu Yaduru Ma'a 'illatihi Wujudan wa 'Adaman", artinya Hukum itu mengikuti alasan rasional ('illat) yang menjadi landasanya, bila alasan rasionalnya ('illat) ada, maka hukumnya ada, bila tidak ada alasan rasionalnya, maka hukumnya pun tidak ada.

Alasan rasional ('Illat) suatu hukum itu ada yang disebutkan dengan jelas di dalam teks hukum, 'illat ini dinamakan 'Al-'illat Al-Manshushah' atau alasan rasional yang eksplisit. Selain itu, adapula 'illat yang tidak disebutkan secara jelas di dalam teks hukum, tetapi ada semacam isyarat yang menunjukkan adanya alasan rasional itu. Ada pula 'illat yang tidak disebutkan dalam teks hukum, baik secara jelas (eksplisit) maupun secara isyarat (implicit), maka harus dicari dan ditemukan 'illat tersebut dengan menggunakan metode penemuan alasan rasional('illat) tertentu yang sudah dijelaskan oleh ahli hukum Islam.

Metode atau cara menemukan dan mencari 'illat ini merupakan hal yang sangat penting untuk diketahui, terutama bagi orang yang ingin menggali dan mengembangkan hukum

${ }^{1}$ Ibnu Hazm, al-Ihkam Fi Ushul al-Ahkam, hal;601-605, juz 8, (Beirut: Dar al-Kutub al-ilmiyah), 
Islam sesuai dengan perubahan sosial yang terjadi sepanjang zaman. Dengan dicari dan ditemukannya alasan rasional ('illat) dari suatu teks hukum, maka cakupan hukumnya dapat diperluas agar dapat mencakup hal-hal baru yang tidak tertulis di dalam teks. Dalam tulisan sederhana ini akan dibahas bagaimana metode menemukan alas an rasional ('illat), atau bagaimana cara mecari dan menemukan 'illat tersebut, apakah setiap teks hokum (nash) dapat dicaridan ditemukan 'illatnya? Atau apakah tujuan pencarian 'illat itu? Pembahasannya difokuskan pada penjelasan yang diberikan di dalam buku ushul fiqih bermazhab Hanafi, yaitu 'Ushul al-Sarakhsi', ditambah dengan buku-buku Ushul Fiqih lain sebagai pembanding dan pelengkap.

\section{PEMBAHASAN}

Buku 'Ushul al-Sarakhsi' dalam suatu riwayat disebut juga 'Bulugh-al-sul fi al-ushul', adapula yang menamakannya 'Tamhid al-Fushul fi Ushul', namun nama buku ini telah dikenal dikalangan ulama ushul fiqih dengan sebutan 'Ushul al-Sarakhsi'. Pengarangnya adalah Syamsu al-a-immah Abu Bakar Muhammad bin Abi Sahal Al- Sarakhsi. Kata AlSarakhsi berasal dari kota kelahirannya 'Sarakhsi' yang terletak di daerah Khurusan, Persia. Ia telah banyak menulis buku, diantaranya yang popular adalah buku fiqih yang bermazhab Hanafi 'Al-Mabsuth' yang terdiri dari 14 jilid ${ }^{2}$.

A. Teks Hukum (Nash) dan Alasan Rasional ('Illat)

Pembicaraan mengenai metode penemuan alas an rasional dalam hokum Islam, atau bagaimana cara mencari dan menemukan 'illat tidak terlepas dari masalah 'apakah setiap teks Hukum (nash) dapat dicari dan ditemukan 'illatnya?' Dalam hal ini terdapat tiga pendapat ulama ahli hokum Islam: ${ }^{3}$

1) Umumnya semua teks hukum dapat dicari dan ditemukan 'illatnya, kecuali ada dalil tertentu yang melarang mencarinya. Inilah pendapat mayoritas Ulama Ushul Fikih

2) Teks hukum itu tidak boleh dicari 'illatnya, kecuali ada dalil tertentu yang menunjukkan sesuatu itulah yang menjadi alas an rasional('illat)nya.

3) Teks Hukum tidak boleh dicari-cari alas an rasionalnya ('illatnya), karena Nabi Muhammad, s.a.w melarang umatnya banyak bertanya, atau mempertanyakan secara mendalam mengapa hal ini diperintah dan mengapa hal itu dilarang, dalam hal ini termasuk larangan mencari alas an rasional ('illat) dari suatu ketentuan syari'at. Di dalam Sunnah /haditsnya, nabi Muhammad, s.a.w bersabda :

“Terima sajalah apa yang telah aku berikan kepadamu, sesungguhnya yang membinasakan umat sebelum kamu adalah karena mereka banyak bertanya dan berbeda pendapat dengan Nabinya. Untuk itu apa saja yang telah aku perintahkan,

${ }^{2}$ Al-Sarakhsi, Ushul Al-Sarakhsi....1372, uz 1, hlm.4-5

${ }^{3}$ Ibid, juz 2, hlm.144-145, Abu Zarah, Ushul al- Figh, hlm.178 dan 188. 
kerjakanlah sejauh kemampuanmu, dan hal-hal yang telah aku larang, tiggalkanlah" (terlampir).

Menurut penulis, pada dasarnya seluruh teks hukum (nash) itu boleh dicari alasan rasionalnya ('illatnya). Alasannya karena banyak Teks yang membolehkan melakukan qiyas (analogy), baik dari Al-Qur'an maupun Sunnah Nabi (Hadits). Seperti: Fa'tabiru ya ulil abshar! (ambillah perbandingan/pelajaran wahai orang-orang yang berakal) (alHasyar: 2). Menurut mayoritas Ulama(jumhur), kata 'Fa'tabiru' berarti 'Faqisu' (lakukanlah qiyas/ perbandingan). Apabila diperintahkan untuk melakukan qiyas berarti diperintahkan juga untuk mencari alas an rasional ('illat) dari suatu teks hukum, karena tidak mungkin melakukan qiyas apabila tidak diketahui alas an rasionalnya ('illatnya), sesuai dengan kaedah 'Ma La yatimmu al-wajibu illa bihi, fa huwa wajib, artinya sesuatu yang menyempurnakan yang wajib, maka dia pun mnjadi wajib. Maksudnya, kalau melakukan qiyas (analogy) itu diperintahkan atau diwajibkan, maka mencari alas an rasional ('illat) juga menjadi wajib, karena tidak mungkin dilakukan qiyas kalau tidak dicari 'illatnya. Kaedah lain, Al-amru bisyai-in, amru biwasa'ilihi' artinya, bila diperintah melakukan sesuatu, maka itu berarti juga diperintah melakukan segala sarana (wasilah) yang dapat mewujudkan perintah tersebut. Dalam hal ini, bila ada perintah untuk melakukan qiyas, maka itu juga berarti perintah untuk mencari alas an rasional('illat), karena tidak mungkin melakukan qiyas, bila tidak diketahui 'illatnya.

Imam Al-Sarakhsi sendiri memilih pendapat pertama ini, alasanya: 'Inna al- dalil alladzi dalla 'ala shihhati al-qiyas wa jawaz al-'amal bihi, yakunu dalilan 'ala jawaz al-ta'lil fi kulli ashlin'4. Artinya, Sesungguhnya dalil yang menunjukkan sahnya melakukan praktik qiyas dan boleh mengamalkannya, menjadi dalil juga tentang bolehnya mencari alas an rasional ('illat) pada setiap teks Hukum. Al-Sarakhsi juga membantah pendapat kedua yang berargumentasi bahwa mencari 'illat dapat mengubah hukum yang sudah ditetapkan dalam teks (nash), keadaannya sama seperti mengambil makna majazi dan meninggalkan makna hakiki. Al-Sarakhsi mengatakan bahwa alasan mereka itu tidak benar dengan ungkapan "kalamun bathil, karena mencari dan menemkan alas an rasional ('illat) tidak berarti mengubah hukum yang sudah ditetapkan dalam nash ${ }^{5}$. Sedangkan pendapat ketiga adalah pendapat mereka yang tidak menerima qiyas sebagi landasan argumentasi (hujjah), yang biasa disebut sebagai kelompok yang menolak praktik qiyas (Nufat al-qiyas).

Berangkat dari masalah ini, para ahli Hukum Islam membagi teks(nash) al-Quran dan sunnah itu kepada 2 macam:

\footnotetext{
${ }^{4}$ Al-Sarakhsi, Ibid.

${ }^{5}$ Ibid, hlm.146
} 
a. Nash yang Ta'aqquli, (teks yang rasional), yaitu nash yang bisa dicari dan difikirkan alas an rasionalnya ('illatnya). Semua nash bisa dicari dan ditemukan'illatnya, tetapi masih ada beberapa hal yang belum dapat diketahui 'illatnya sampai sekarang.

b. Nash yang Ta'abuddi, (teks yang supra rasional), yaitu nash yang tidak bisa dicari alas an rasionalnya ('illatnya), kebanyakan hal ini terdapat dalam masalah ibadah. Seperti apakah alas an rasional ('illat) bilangan raka'at shalat, misalnya mempertanyakan mengapa shalat subuh itu 2 raka'at, shalat zuhur 4 raka'at, maghrib 3 raka'at, dsb. Mengapa nisab zakat sapi / kerbau 5 ekor, kambing 40 ekor. Apa alasan rasional ('illat) diharamkannya babi, dsb.

B. Tujuan Pencarian 'Illat

Mengapa harus dicari dan ditemukan alasan rasional ('illat) dari suatu teks ? Pencarian 'illat dari suatu teks/nash mempunyai 2 tujuan:

a. Untuk dapat melakukan qiyas. Bila alasan rasional ('illat) telah dicari dan ditemukan, dan 'illat tersebut tidak terbatas adanya pada masalah ashal saja (ghairu maqsurah 'ala al-ashli), tetapi dapat pula diproyeksikan/diperluas pada masalah lain (al-far'u), maka qiyas dapat dilakukan. 'Illat disini dapat dinamakan sebagi 'illat qiyasi'.

b. Untuk meneliti kembali alasan rasional ('illat) dari suatu teks hukum, perlu setelah dianalisis apakah alasan rasional ('illat) itu masih ada pada zaman sekarang atau sudah berubah/ bergeser, adanya hanya di zaman dahulu. Bila alas an rasional ('illat)nya masih ada di zaman kini, berarti hukum yang terdapat dalam teks itu masih harus diberlakukan sampai sekarang. Sebaliknya, bila alasan rasional ('illat)nya sudah tidak ada lagi di zaman sekarang, atau sudah seharusnya bergeser dan berubah maka hukumnya juga harus berubah ${ }^{6}$.

Alasan rasional ('Illat) disini hanya terbatas adanya pada masalah ashal, (maqsurah 'ala al- ashl, atau ghairu muta'adiyah), tidak dapat diproyeksikan, tidak dapat diperluas kepada masalah lainnya. 'Illat ini dapat disebut sebagai ' $\underline{\text { Illat }}$ $\underline{\text { tasyri'I }}$ yaitu alasan rasional yang menjadi landasan disyari'atkannya suatu hukum.

Buku-buku Ushul Fiqih klasik, termasuk 'Ushul al- Sarakhsi', lebih banyak menjelaskan alasan rasional ('illat) untuk digunakan dalam praktek qiyas. Oleh sebab itu pembahasan tentang 'pencarian 'illat' ditempatkan oleh pengarangnya pada bagian dari bab qiyas ${ }^{7}$. sedangkan 'illat tasyri'i tidak atau kurang mendapat perhatian dan kurang mendapat tempat dalam buku-buku ushul fikih klasik, sehingga tidak ada pembahasan khusus. Pembahasan 'illat tasyri'i yang cukup

${ }^{6}$ Dr. M. Musthafa Syalabi, Ta'lil al-Ahkam, hlm.12

7 Al- Sarkhsi menjelaskan: pencarian 'Illat untuk dapat melakukan qiyas (innama al-ta'lil lita'diyatil hukmi...), hlm.146 
memadai dapat dilihat dalam buku 'Ta'lil al-Ahkam' karangan DR. Muhammad Mushtafa Syalabi.

C. Metode Menemukan alasan rasional ('Illat)

Imam Al- Sarakhsi tidak menjelaskan metode/ cara mencari dan menemukan alasan rasional ( 'illat) secara rinci, masalah ini dibahas dalam 5 halaman dari kitabnya di bawah sub judul 'Faslun fi Ta'lil al- Ashli'. Metode atau Cara menemukan alasan rasional ('illat) itu dapat dijelaskan sebagai berikut: ${ }^{2}$

1) Melalui teks hukum (Nash), artinya alasan rasional ('illat) dapat dicari dan ditemukan dengan memperhatikan teks Al-Qur'an dan atau teks Sunnah/Hadits. Misalnya sebagai contoh firman Allah dalam surat al-hasyar ayat 7: Kaila Yakuna Dulatan Bainal Aghniya'I Minkum, artinya; " Agar harta kekayaan itu jangan hanya beredar diantara orang-orang kaya saja diantara kamu" (QS 59:7). Ayat ini menjelaskan bahwa harta rampasan perang (al-fai) yang diperoleh harus dibagi atau didistribusikan untuk Allah, RasulNya, Karib kerabat, anak yatim, fakir miskin dan Ibnu sabil. Apa alas an rasionalnya ('illatnya) harta itu harus dibagi? atau mengapa harta itu mesti dibagi? Jawabannya diperoleh dari Nash ayat itu sendiri, yaitu agar harta itu jangan hanya beredar di tangan orang-orang kaya saja di antara kamu, inilah yang menjadi 'illatnya (alasan rasionalnya). Namun, imam Al-Sarakhsi tidak menjelaskan tanda-tanda adanya suatu alasan rasional ('illat) yang disebutkan dalam nash. Tanda-tanda adanya alasan rasional ('illat) disebut di dalam teks hukum ini dapat dilihat pada buku ushul fiqih lain sepert kitab 'Irsyad Al-Fuhul', karya imam al-Syaukani yang menyebutkan tanda-tanda itu., misalnya: di dalam teks al-Qur'an atau Sunnah terdapat kata-kata yang menunjukkan alasan rasional ('illat), seperti kata 'Kay' (agar supaya), atau kata 'Min Ajli, atau Li Ajli' (karena itu), dan kata kata lainnya yang semakna9.

2) Melalui 'Fahwa al-Nash', (isyarat Nash), maksudnya teks/nash al-Qur'an atau sunnah tidak menyebutkan alasan rasional ('iilat) secara jelas, tetapi hanya memberikan isyarat saja. Contoh di dalam Sunnah/Hadits Nabi yang menjelaskan tentang adanya tikus yang masuk ke dalam minyak makan (minyak goreng), menurut Nabi, 'Jika minyak itu kering (beku), lemparkanlah (buanglah) tikus itu dan kotoran yang ada disekitarnya, lalu pergunakanlah minyak yang masih tersisa, tetapi apabila minyak itu encer (cair), maka tumpahkan (buanglah) minyak itu! Di dalam hadits ini ada isyarat yang menunjukkan adanya alasan rasional ('illat), yaitu masuknya najis, dalam hal ini tikus, ke dalam minyak makan yang membuat minyak itu tidak suci atau tidak bersih lagi sehingga tidak dapat dikonsumsi. Kalau diperhatikan buku-buku Ushul fikih lain, dipergunakan istilah 'isyarat' atau 'Al-

${ }^{8}$ Al-Sarakhsi, Ibid, hlm.149

${ }_{9}^{9}$ Al-Syaukani, Irsyad Al-Fuhul...1328H, hlm.397 
Ima' (tanda-tanda/indicator), sedangkan imam Al-Sarakhsi dalam kitab ushul fikihnya menggunakan istilah 'Fahwa al- Nash'. Menurut penulis hal ini hanyalah perbedaan istilah (terminology) saja, sedangkan substansinya sama.

3) Al-Istidlal bi Hukmi Al-Nash, dalam hal ini imam Al-Sarakhsi tidak menjelaskan lebih lanjut apa yang dimaksud dengan istilah "al-Istidlal" ini. Penulis berusaha mencari tahu apa yang dimaksud dengan istilah ini. Penulis dapat mengetahui maksud istilah ini setelah membaca buku ushul Fikih karya imam Al-Ghazali, yaitu 'Al-Mustahfa Min 'ilmi al-Ushul. Imam Al-Ghazali menjelaskan cara mencari dan menemukan alasan rasional('illat), diantaranya apa yang disebut dengan istilah 'Tanqih al-Manath'. Di akhir penjelasannya dikatakan oleh imam al-Ghazali bahwa Abu Hanifah dan ulama Hanafiyah menyebut metode Tanqih Al-Manath ini dengan nama 'Al-Istidlal'. Imam al-Ghazali mengatakan :" wa atsbata Abu Hanifah Haza Al-Namtha min Al- Tasharruf wa sammahu Istidlalan", artinya imam Abu Hanifah menetapkan metode penemuan alasan rasional('illat) seperti ini (Tanqih al-Manath) dan menamakannya dengan istilah Istidlal. ${ }^{10}$.

Berdasarkan keterangan di atas dapat disimpulkan bahwa yang dimaksud dengan istilah 'Al-Istidlal' dalam buku ushul fikih al-Sarakhsi adalah sama dengan istilah 'Tanqih al-Manath' dalam buku ushul yang lain, karena al-Sarakhsi adalah ulama yang mengikut cara berfikir Abu Hanifah (bermazhab Hanafiyah). Hal ini menghendaki penjelasan tentang apa yang dimaksud dengan metode 'Tanqih $\mathbf{A l}$ Manath'.

Tanqih Al-Manath, adalah suatu metode yang digunakan untuk mencari dan menemukan alasan rasional ('illat) yang menjadi landasan suatu hukum, dengan cara mengumpulkan dan menginventaris beberapa kemungkinan (alternatif) yang dapat dijadikan sebagai alasan rasional('illat). Kemudian beberapa hal yang mungkin dapat dijadikan sebagai 'illat itu diuji, diverifikasi atau diseleksi (diTanqih) mana yang lebih tepat, atau mana yang lebih mendekati kebenaran ${ }^{11}$. Contoh:dalam hal ini adalah kasus seorang Arab Baduy (A'raby) yang datang kepada Nabi Muhammad, s,a,w mengadukan bahwa ia melakukan sexual intercourse (besenggama) dengan isterinya di siang hari bulan Ramadhan. Nabi menyuruhnya untuk membayar kaffarat (denda) berupa, memerdekakan budak, bila tidak sanggup, berpuasa 2 bulan berturut-turut; dan bila tidak sanggup juga, ia harus memberi makan 60 orang miskin (hadist terlampir). Para ulama berusaha mencari 'illatnya, mengapa orang itu harus membayar kaffarat? Beberapa hal yang mungkin dijadikan sebagi 'illat, dikumpulkan, misalnya: a. karena ia orang Arab. b. karena ia bersenggama dengan istrinya. c. karena ia merusak kehormatan bulan Ramadhan.

${ }^{10}$ Al-Ghazali, Al-Musthafa, hlm.397

${ }^{11}$ Lihat Al-Ghazali, Ibid, Al-Syatibi, Al-Muwafaqat, Juz 4, hlm.49-50 
Kemungkinan tersebut diteliti kembali, apakah mungkin 'illatnya karena orang Arab? kenyataannya Islam tidak membedakan antara orang Arab atau non Arab dalam menerapakan hukum Islam. Jadi tidak ada beda (disebut 'ilgha al-fariq) antara orang Arab dan non Arab kecuali kepatuhannya (Taqwa) kepada Allah, seperti sabda Nabi dalam Hadistnya. Kemungkinan b diteliti lagi, apakah mungkin ia bersenggama dengan istrinya? Ternyata tidak demikian, walaupun ia bersenggama dengan wanita lain, tetapi hukumnya tetap membayar kaffarat. Alternatif a dan b tidak dapat diterima sebagai 'illat, lalu diteliti alternatif $c$, ternyata alternatif ini dapat diterima sebagai 'illat, karena ia tidak menghargai perintah Allah, dimana Allah membolehkan bersenggama dengan isteri dimalam Ramadhan (QS. AlBaqarah: 187,Al-Hajj: 32). Dengan melanggar larangan Allah berarti dia tidak menghormati kehormatan bulan Ramadhan (hatku hurumat Ramadhan). Para Ulama sepakat bahwa tiak mungkin seluruh alternatif itu dapat menjadi 'illat, tetapi yang akan menjadi 'illat salah satu dari beberapa alternatif tersebut ${ }^{12}$. Dalam memilih salah satu alternatif itu harus didukung denagn dalil lain baik dari Al-Qur'an maupun dari Hadist. Dalil yang mendukung pilihan itu disebut juga ' Dalil Pembeda' (al- Dalil al- mumayyiz) ${ }^{13}$.

Abu Hanifah dan para pengikutnya (Al-Hanafiyah), Imam Malik, (termasuk Malikiyah) serta imam Al-Tsauri memproyeksikan'iilat ini (termasuk kehormatan Ramadhan) kemasalah lain, yaitu makan dan minum dengan sengaja disiang Ramadhan. menurut mereka orang yang berbuka dengan makan dan minum secara sengaja disiang Ramadhan, maka mereka wajib membayar kafarat pula sama seperti orang yang besenggama disiang Ramadhan. Qiyas ini landasannya adalah 'illat tersebut, yaitu sama-sama merusak kehormatan bulan Ramadhan ${ }^{14}$.

Hal tersebut di atas memperkuat kesimpulan yang telah dijelaskan sebelumnya, yaitu Hanafiyah juga menggunakan metode pencarian 'illat yag disebut 'Tanqih al Manath', hanya saja dengan nama 'Al-Istidlal'. Sedangkan Imam Fakhru al-Razi menamakan 'Tanqih Al-Manath'. Ini dengan sebutan 'Al-Sabru-wa al-taqsim, atau dengan kata lain metode Tanqih Al Manath sama dengan 'al-sabru wa al-taqsim ${ }^{15}$.

Al-Sarakhsi dalam buku Ushul Fiqihnya hanya menyebut tiga cara mencari 'illat seperti tesebut diatas (melalui nash; fahwa nash; dan al-istidlal). Namun dalam buku Ushul fiqih lainya dijumpai cara lain seperti 'Takhrij al-Manath' dan 'Tanqih alManath. Adalah perlu untuk menelaskan pengertian 'Takhrij Al-Manath' dan

\footnotetext{
12 Al-Sarakhsi, Ushul Al-Sarakhsi.....1372H, h 176

${ }^{13}$ Ibid , hlm.146-147

${ }^{14}$.Dr. Mushtafa Sa'id Khin, Atsar al-Ikhtilaf fi QAwa-id al-Ushuli yah fi Iktilaf al-fuqaha', hlm.484485, Al-Sarakhsi, hlm.153-154

${ }^{15}$ Al-Syaukani, Irsyad Al-Fuhul.....1328H, hlm.199 dan 206
} 
'Tanqih al-Manath', sebelum membandingkan cara mencari 'illat menurut jumhur Ulama ushul (selain Hanafiyah)

Takhrij Al-Manath adalah cara mencari 'illat dengan cara mencari satu hal yang mungkin itu diuji, diteliti apakah cocok untuk dijadikan 'illay atau tidak. Jika satu kemungkinan itu ternyata tidak tepat, maka dicarilah kemungkinan kedua, lalu diuji dan diteliti lagi. Jika telah diteliti, ternyata kemungkinan ini dapat dijadikan 'illat, maka usaha pencarian 'illat dihentikan. Namun bila tenyata tidak dapat dijadikan 'illat, maka dicarilah kemungkinan ketiga, keempat dan seterusnyat, sampai berhasil ditemukan 'illat.

Metode Takhrij al- Manath ini sebenarnya kebalikan dari metode Tanqih alManath. Kalau dalam 'Tanqih al-Manath' dimulai dengan mengumpulkan sejumlah hal yang mungkin menjadi 'illat, setelah terkumpul baru diuji/ diteliti satu persatu kemungkinan tersebut, lalu dipilih salah satu setelah diajukan dalil lain yang mendukung pilihan itu. Sedangkan dalam Takhrij Al-Manath tidak perlu mengumpulkan sejumlah kemungkina dulu, tetapi langsung dicari satu kemungkinan yang bisa menjadi 'illat, lalu satu kemungkinan itu langsung diuji / diteliti. Jika hal itu cocok untuk dijadiak 'illat, selesailah sudah usaha pencarian 'illat. Namun bila hal itu tidak cocok untuk dijadikan 'illat, barulah dicari kemungkina kedua, ketiga, keempat, dst, sampai berhasil dijumpai 'illat.

Al-syaukani mengatakan bahwa metode Takhrij al-Manath ini sama dengan metode 'Al-Munasabah', yaitu mencari dan memilih 'illat yang lebih relevan dengan tujuan syari' at (bi ri'ayah maqashid al-Syari'ah) ${ }^{16}$.

Tanqiq al-Manath, adalah metode pencarian 'illat dengan memperhatikan dan membuat definisi dari sesuatu makna / kata yang terakhtub dalam nash. Misalnya nash yang menyebutkan boleh memendekkan shalat (qashar) bila seseorang sedang dalam perjalanan (QS. An-Nisa': 101). 'Illatnya adalah 'safar' (dalam perjalanan), tetapi apakah yang dimaksud dengan 'safar' itu? Apakah safar itu ditentukan dengan jarak tempuh (sekian KM atau Mil), atau ditentukan dengan waktu tempuh (sekian hari perjalanan)? Apakah pengertian safar pada zaman Nabi dulu masih harus dipertahankan untuk zaman teknologi modern seperti sekarang ini? Kesemua masalah ini dapat dijelaskan dengan embuat definisi safar (Tanqih al-Manath)

Banyak riwayat yang menjelaskan tentang safar itu, diantaranya ada yang membatasi dengan 3 mile, 446 mil, perjalanan sehari semalam, 3 hari 3 malam dengan berjalan kaki, dsb. Bila safar telah sampai menempuh jarak tersebut baru boleh mengqashar shalat. Namun menurut Ibnu Hazm semua riwayat itu tidak benar, tidak ada dalilnya dalan Al-Qur'an atau hadist yang shahih, semua itu 
hanyalah penjelasan para sahabat Nabi. Bahkan Ibnu Umar mengqashar shalat dalam perjalanan hanya satu jam ${ }^{17}$.

Di zaman sekarang situasi telah jauh berubah, dahulu orang-orang bersafar dengan unta, kuda, keledai, atau jalan kaki, tetapi sekarang orang menggunakan pesawat terbang, mobil cepat, kereta api ekspres,mobil bus mewah dsb. Hal ini mengharuskan ditinjau kembali pengertian safar itu, dibuat kembali definisi yang relevan dengan zaman sekarang.

Ketiga metode ini (Tanqih al-Manath, Takhrij al-Manath, tahqiq al-Manath) sebenarnya bisa dipergunakan sejalan dalam satu kegitan. Maksudnya ketika mencari 'illat dipergunakan tanqih al-manath, pada waktu yang sama juga bisa digunakan takhrij al-manath atau tahqiq al-manath. Oleh sebab itu bila Al-Sarakhsi tidak menyebut ketiga istilah ini dalam bukunya, namun menurut penulisketika hal ini telah dapat diwakili dengan istilah itu adalah sama dengan 'Tanqih al-Manath.

Berdasarkan uraian-uraian terdahulu, dapatlah dibuat gambaran singkat tentang cara menemukan 'illat menurut Hanafiyah, dalam hal ini diwakili oleh Al-Sarahksi, dibandingkan dengan pendapat jumhur Ulama ushul fikih secara global sebagai berikut:

\begin{tabular}{|c|c|c|c|}
\hline No & Hanafiyah (Al-Sarakhsi) & Jumhur & keterangan \\
\hline 1. & $\begin{array}{l}\text { Melalui nash } \\
\text { Melalui fahwa al-nash }\end{array}$ & $\begin{array}{l}\text { Melalui nash } \\
\text { Isyarat al-nash } \\
\text { atau al-ima' }\end{array}$ & $\begin{array}{l}\text { 1. Al- Amidi dan } \\
\text { Al-Syaukani } \\
\text { menempatkan ijma' } \\
\text { pada urutan } 1 \text {, dan } \\
\text { nash pada urutan ke } \\
2 .{ }^{18}\end{array}$ \\
\hline 3 & Al-Istidlal & $\begin{array}{l}\text { Tanqih al- } \\
\text { Manath } \\
\text { Takhrij al- } \\
\text { Manath } \\
\text { Tahqiq al- Manat }\end{array}$ & $\begin{array}{l}\text { 2. Tanqih al- } \\
\text { Manath sama dengan } \\
\text { al-Munasabah (Al- } \\
\text { Syaukani) } \\
\text { 3. Tanqih wa al- } \\
\text { Taqsim (Al-Razi) }\end{array}$ \\
\hline
\end{tabular}

Usaha menemukan 'illat sebenarnya merupakan ijtihad yang dilakukan oleh para ahli hukum Islam, baik pada 'illat yang tidak tersebut dalam nash (al-'illat almustanbathah), maupun pada 'illat yang tersebut jelas dalam nash (al-'illat almansushah). Hanya saja pada ijtihad yang dilakukan terhadap 'illat yang sudah tersebut didalam nash secara jelas (eksplisit) lebih banyak berupa 'Tahqiq al-Manath.

${ }^{17}$ Ibnu Hazmin, Al-Muhalla, juz 3, h.243-245

${ }^{18}$ Al-Amidi, Al-Ihkam, Juz 3, h.94, Al-Syaukani, Irsyad Al-Fuhul....1328H, hlm.195 


\section{PENUTUP}

Pada akhir pembahasan ini dapatlah ditarik beberapa kesimpulan diantaranya:

Metode atau Cara menemukan alas an rasional ('illat) yang disebutkan dalam buku AlSarakhsi hanya 3 cara: melalui nash; fahwa al-nash; dan al-istidlal bi hukmi al-nash.

Metode atau Cara menemukan 'illat lain yang disebutkan oleh Jumhur Ulama (Tanqih al-Manath, Takhrij al-namath dan Tahqiq al-Manath) dapat dimasukkan ke dalam 'Alistidlal bi hukmi al-nash.

Semua metode atau cara menemukan alas an rasional dalam hokum Islam ('illat) ini adalah usaha ijtihadiyah, hasil pemikiran para ahli hukum Islam dan masih dapat dikembangkan sesuai dengan perkembangan zaman. 
FITRAH Vol.01 No. 1 Januari-Juni 2015

\section{DAFTAR PUSTAKA}

Abu Zahrah, Ushul al-Figh, Daru al-Fikri Al-Arabi, Kairo, t.tp, t.th.

Al-Ghazali, Al-Mushtashfa, maktabah al-jundi, Kairo, 1971

Al-Hamidi, Al-Ihkam Fi Ushul Al-Ahkam, Muhammad Ali Subaih wa awladuh, t.t, t.tp1968

Ali Hasaballah, Ushul Al-Tasyri' Al-Islami, Daru Al-Ma'arif, Kairo, t.tp, 1985

Al-Sarakhsi, Ushul Al-Sarakhsi, Daru Al-Kitab Al-Arabi, Kairo, t.tp, 1372 H

Al-Syartibi, Al-Muwafaqat, Daru Al-Fikri, Kairo, t.tp, t.th.

Al-Syaukani, Irsyad Al-Fuhul, Sa'adah, Kairo, t.tp, 1328 H

DR. Muhammad Musthafa Syalabi, Ta'lim Al-Ahkam, Daru Al- Nahdah Al-Arabiyah, Beirut, t.tp, 1981

DR. Musthafa Sa'id Khin, Atsar Al-Ikhtilafi Fi Qawa-id Al-Ushuliyah Fi Ikhtilafi Al-Fuqaha', Muassasah Al-Risalah, Beirut, Cet IV, 1985

Ibnu Hazmin, Al-Muhalla, Daru Al-Fikri, Kairo, t.tp t.th. 